\title{
The regulation of brood reduction in Booted Eagles Hieraaetus pennatus through habitat heterogeneity
}

\author{
EVA CASADO, ${ }^{1 *}$ SUSANA SUÁREZ-SEOANE, ${ }^{2}$ JULIEN LAMELIN ${ }^{3}$ \& MIGUEL FERRER ${ }^{1}$ \\ ${ }^{1}$ Dept. of Biodiversity Conservation, Estación Biológica de Doñana, CSIC Avda. de Ma Luisa s/n, \\ Pabellón del Perú, 41013 Seville, Spain \\ ${ }^{2}$ Área de Ecología, Facultad de Ciencias Biológicas y Ambientales, Universidad de León, \\ Campus de Vegazana s/n, 24071 León, Spain \\ ${ }^{3}$ Institut National Agronomique Paris-Grignon University, Paris 6, France
}

\begin{abstract}
Brood reduction, the death of one or more chicks through siblicide or starvation, can occur through density-dependence in fecundity. Brood reduction may arise in territorial breeding systems either as a response to a high level of territorial interference in a situation of high density or as a result of habitat heterogeneity. To test the predictions of the two main hypotheses that attempt to explain how density-dependent fecundity is generated, the Habitat Heterogeneity Hypothesis ( $\mathrm{HHH}$ ) and the Individual Adjustment Hypothesis (IAH), we analysed the relationship between density and fecundity in an expanding population of Booted Eagles in Doñana National Park, Spain, using an 18-year data series. We also studied the occurrence and frequency of brood reduction in the same Booted Eagle population to appreciate further its effects and the factors that influence its occurrence and frequency. Our results support the $\mathrm{HHH}$ in the present situation of high density, as fecundity in the better territories (older and more frequently occupied) was higher than in low quality territories and was not affected by population density in high density periods. Nevertheless, the fecundity of high quality territories was affected (although not significantly) by population density in periods of low density, suggesting that the IAH was supported when only high quality territories were occupied. Older territories were used more frequently and chicks in these areas hatched earlier and suffered lower mortality than in new territories. We found a significant negative relationship between mean fecundity and its skewness, a finding that also supports HHH. During years of food shortage, less frequently occupied territories suffered higher rates of brood reduction. Brood reduction in this Booted Eagle population was a consequence of the heterogeneous structure of the habitat, with some territories having a higher probability of brood reduction than others. Parental nutritional condition did not affect brood reduction. The effect of brood reduction on nestling quality and population dynamics is also discussed.
\end{abstract}

Keywords: density dependence, fecundity, nutritional condition.

Despite the high cost of rearing nestlings, overproduction occurs in raptor species that suffer from brood reduction, the death of one or more chicks through siblicide or starvation (Edwards \& Collopy 1983, Simmons 1988). At egg-laying, future food levels cannot be predicted and so parents may lay a clutch of optimistic size (Lack 1947, Mock \& Forbes 1995).

*Corresponding author.

Email: casado@ebd.csic.es
Variations in the frequency of brood reduction within a population will to some extent influence population fecundity.

Changes in fecundity lead to density-dependent processes in natural populations (Sinclair 1989). The effect of density-dependent fecundity on population regulation has been well described (Newton 1991, Ferrer \& Donázar 1996, Rodenhouse et al. 1997, Newton et al. 1998) and two major hypotheses, not necessarily mutually exclusive (Rodenhouse et al. 
2003), have been proposed to explain how densitydependent variation in fecundity arises. Individuals will be less fecund in an increasing population (Lack 1966), either because of increasing intraspecific interference affecting all pairs - the Individual Adjustment Hypothesis (IAH; Lack 1954, 1966, Fretwell \& Lucas 1970, Haller 1996, Both 1998, Fernandez et al. 1998) - or because an increasing number of breeding pairs nest in poorer territories with lower fecundity prospects - the Habitat Heterogeneity Hypothesis (HHH; Andrewartha \& Birch 1954, Pulliam \& Danielson 1991, Dhondt et al. 1992, Ferrer \& Donázar 1996, Rodenhouse et al. 1997, Krüger \& Lindström 2001, Horne \& Fielding 2002). Both mechanisms result in a decrease in mean fecundity, although predictions for other reproductive parameters differ between hypotheses (Ferrer \& Donázar 1996, Ferrer et al. 2006).

There has been much research on the regulation mechanisms operating on both short-lived (Goodburn 1991, Dhondt et al. 1992, Both 1998) and long-lived (Ferrer \& Donázar 1996, Haller 1996, Krüger \& Lindström 2001, Penteriani et al. 2002, Penteriani et al. 2003) bird species, yielding contradictory results within each group (Ferrer \& Donázar 1996 vs. Haller 1996, Dhondt et al. 1992 vs. Both 1998). Differences between studies may be due to differences in habitat suitability (which must be constant within patches during the study period), in population status (HHH is easier to detect in a saturated population; Rodenhouse et al. 1997) or in differences in the tests employed (Ferrer et al. 2006).

The aim of this study was to investigate the densitydependence of brood reduction to assess the mechanisms by which brood reduction regulates population growth in a territorial raptor, and to identify factors that might be related to the occurrence and frequency of brood reduction. Our aim was to contribute to the debate concerning $\mathrm{IAH}$ and $\mathrm{HHH}$ by using new tests (Ferrer et al. 2006) in an expanding population. To this end, we analysed fecundity and brood reduction frequency in relation to density in the Booted Eagle Hieraaetus pennatus population in Doñana National Park over an 18-year period. We also investigated the effects of territorial quality, food resources, and birds' nutritional condition on brood reduction.

Population fecundity is partly a function of brood reduction and if the latter is a density-dependent process, then an increase in population density should lead to an increase in the frequency of brood reduction. If the density-dependent fecundity of a population is the result of habitat heterogeneity, then we would expect to find a higher frequency of brood reduction in a subset of territories (defined as low quality territories) rather than in all of them. Otherwise, if intraspecific interference is the primary influence, then brood reduction frequency would be found equally in all nests and/or territories.

Both IAH and $\mathrm{HHH}$ predict a negative relationship between density and fecundity (Dhondt et al. 1992, Ferrer \& Donázar 1996, Both 1998). However, with the $\mathrm{HHH}$, additional patterns are expected for territorial animals. First, fecundity does not decrease in high-quality territories as population densities increase. Secondly, territories that are occupied more often or earlier during population growth have higher fecundity. Thirdly, the fecundity distribution is more left-skewed when mean fecundity is lower. Conversely, the IAH predicts that individuals in all different patches are affected by density roughly to the same extent, that the occupation frequency of available territories does not differ from a random distribution pattern, and that there is no correlation between mean fecundity and the skewness of fecundity distribution.

\section{METHODS}

The Booted Eagle is a medium-size territorial raptor with marked sexual dimorphism (males $709 \mathrm{~g}$, females 975 g; del Hoyo et al. 1994). Pale and dark morphs occur with several intermediate plumages. Of the 87 adults captured in Doñana National Park, 13.8\% were dark morph (own data). Juveniles are also polymorphic and very similar to adults. Most birds migrate to sub-Saharan Africa, leaving the breeding grounds in September and returning in March-April. One month after arrival, the female normally lays two eggs (sometimes one and occasionally three), which hatch after 37-40 days of incubation. Booted Eagles nest in trees in forests mixed with open areas, often in open woodland (Sánchez-Zapata \& Calvo 1999, Suárez-Seoane et al. 2000), and use sites that differ in suitability (Martínez et al. 2006). The species feeds on a broad range of prey (Martínez et al. 2004, Martínez \& Calvo 2005), although the European Rabbit Oryctolagus cuniculus is probably its main prey item (Veiga 1986). In comparative raptor studies of siblicide and brood reduction, the Booted Eagle is considered to exhibit facultative fratricide (Edwards \& Collopy 1983, Simmons 1988). 



\section{Study area}

The study site was the Doñana National Park, southwestern Spain $\left(37^{\circ} \mathrm{N}, 6^{\circ} 30^{\prime} \mathrm{W}\right)$. The only area excluded was that of Marismillas, a pine forest in the most southerly part of the National Park, where Booted Eagle nests were not comprehensively studied during the study period. The size of the study area (Fig. 1) is about 38000 ha and includes five main landscape types: 1) eucalyptus (Eucaliptus spp.) plantations, 2) scattered Cork Oak Quercus suber with scrubland dominated by Genista sp., Rosmarinus sp. and Lentiscus sp., 3) forests of Stone Pines Pinus pinea, 4) coastal sand dunes, and 5) marshland. A more detailed description of the area is presented in Suárez-Seoane et al. (2000). In 2000, this area held $75 \%$ of the Booted Eagle population in the National Park, which was estimated at around 80 pairs (Doñana Biological Station Archives).

\section{Mechanisms of population regulation}

From 1976 to 2000, the breeding population size (number of pairs occupying territories at the beginning of the breeding season), brood size at hatching and number of fledglings (chicks that reached at least 30 days of age, at which time they were ringed) were monitored. Breeding population size and fecundity parameters between 1976 and 1996 were taken from the Doñana field diaries (Doñana Biological Station Archives). The density of the population was measured as the number of breeding pairs in the area, as the size of the study area remained constant. Each spring, all previously known territories were visited to record occupancy and previously unoccupied areas were also checked for new pairs. All nests were visited at least twice by the same person, at the beginning and end of the breeding season, to band the nestlings. From 1996 to 2000 our own team monitored changes

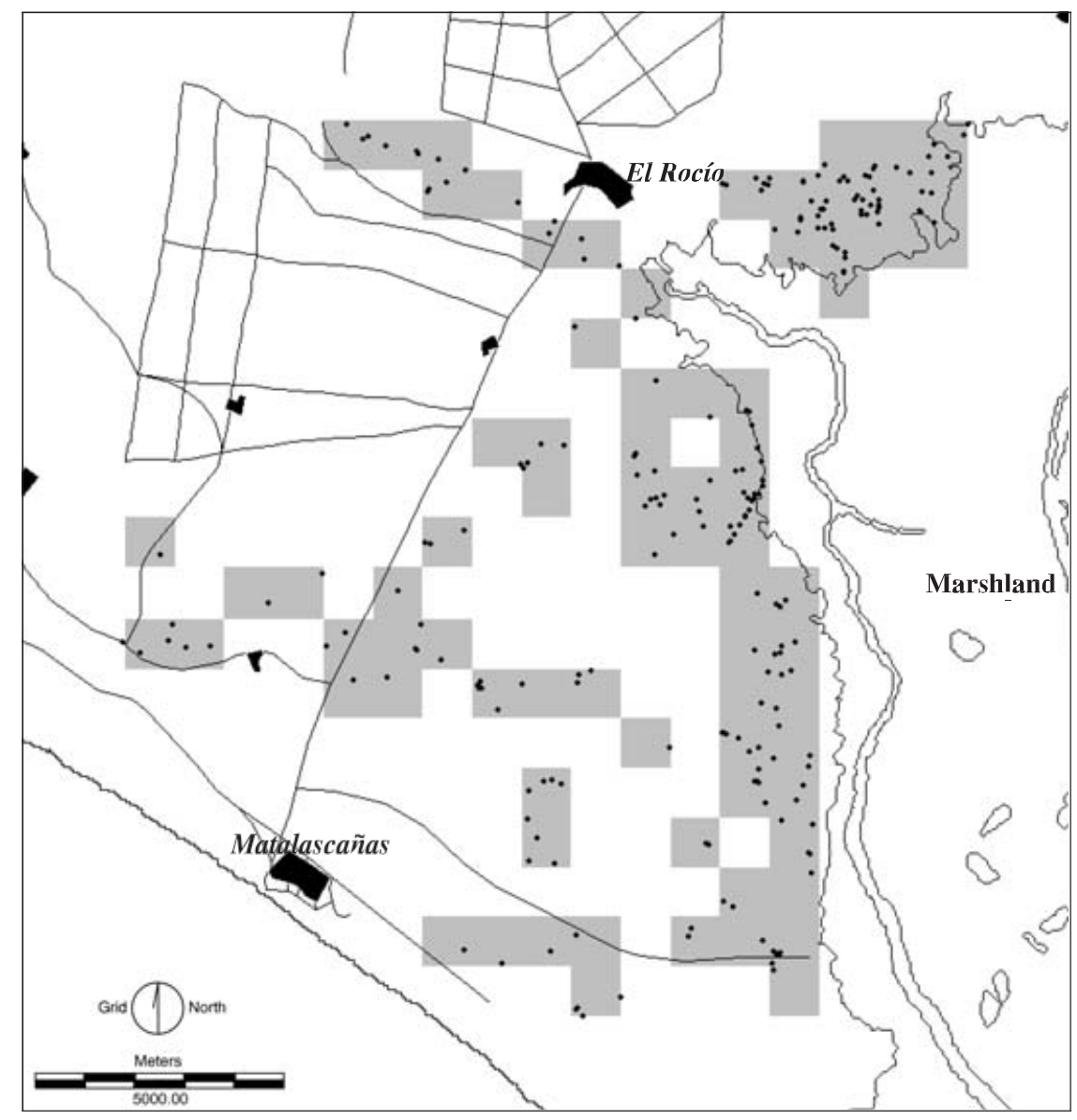

Figure 1. Location of territories. The study area lies within the dotted line. Grey squares are the 1-km² territories used between 1983 and $2000(n=77)$; black dots correspond to nest sites. Black lines are roads and tracks, and polygons are urban areas. 
in the Booted Eagle population. Nest-sites were easily detected due to the conspicuous behaviour of the birds, and the nests themselves were easily distinguishable from those of other raptors because Booted Eagles cover their nests with green leaves. Nest-sites were visited every 2-3 days to check for signs of occupation. Once we suspected incubation had started, we waited for 40 days (the incubation period) before climbing up to the nests for the first time to mark the first chicks. If the chicks had not hatched, we returned at a later date. The laying date of the first egg was recorded in nests where we had previously installed a camera linked to a time-lapse video cassette recorder (Mitsubishi HS-7424EDC). Laying and hatching dates (both converted to the number of days from 1 January) were estimated from the timing of nest visits and examinations of nest contents; we only used dates that we were sure had an error of less than 7 days. The next time the nests were visited was to mark chicks. In all, the nests where eggs and/or chicks were marked were climbed up to four times; the others were only climbed up to three times.

The location of all known nests was recorded using a Garmin III Plus GPS. Territories were identified by mapping the UTM coordinates of nests: territories held potentially more than one nest-site because alternative nests may be used in the same or different years. As the average inter-nest distance was $1.06 \mathrm{~km}$ (Suárez-Seoane et al. 2000), nest coordinates were overlaid with a 1-km grid and all nests within the same 1-km grid square were considered to belong to the same territory.

The skewness of the fecundity distribution was used to discriminate between $\mathrm{HHH}$ and IAH (Ferrer et al. 2006, 2008). To analyse the annual relationship we used the fecundity of all the pairs within a year, whereas when we analysed the territorial effect we used all attempts over the years within a territory. Territories were divided into two groups according to the date of first occupation, older territories being those occupied for the first time in the period 1983 91, and new territories those first occupied in the period 1992-2000. This factor together with the occupation frequency calculated as a percentage were used as measures of territorial quality (Ferrer \& Donázar 1996, Sergio \& Newton 2003).

\section{Brood reduction}

We expressed the brood reduction frequency as the annual percentage of nests suffering from nestling mortality in which more than one sibling hatched. Predation generally results in total brood loss in raptors (Newton 1979) and so nestling mortality from predation and other causes such as abandonment was excluded from the analyses of brood reduction (Viñuela 1999). As in some years data on hatching rates were not available for some nests, we eliminated those years with fewer than five records of brood reduction to avoid any possible bias in our estimates of the annual brood reduction frequency, and so only analysed the years 1983-84, 1988, and 1993-2000 for brood reduction (referred to as the selected years). We determined the yearly mean fecundity as the number of fledglings per breeding pair. From 1997 onwards we marked eggs and/or nestlings to try to identify the hatching order accurately. The mean clutch and brood sizes (at hatching) and fecundity were calculated per territory for the selected years.

We compared brood reduction frequency between good and poor years. A fecundity that is higher or lower than the average annual fecundity is a commonly used method for the yearly classification of quality (e.g. Penteriani et al. 2002), 'good' years being those with a mean fecundity higher than the annual rate, and 'poor' years those with fecundity lower than the annual rate. This method would have led to circular reasoning as fecundity decreased significantly with brood reduction $(r=-0.734, n=10$, $P=0.016$, the year 2000 being removed from this linear regression as it had a very low residual value), and so we excluded those nests where brood reduction occurred from our calculations, to suppress their effect on annual fecundity.

\section{Biochemistry}

During 1996-98 and 2000, we took blood samples from Booted Eagle adults and nestlings to analyse urea and uric acid concentrations in plasma and thus establish an estimate of nutritional condition (Ferrer 1994 and references therein). We extracted nestling blood at ringing. Adults were captured during the nestling period using a net and an alive but unable to fly Eagle Owl Bubo bubo as a lure (further details in Casado et al. 2002).

\section{Food supply}

The European Rabbit has been identified as the main prey item of the Booted Eagle (Veiga 1986). In April 1990, an outbreak of viral hemorrhagic disease in the area of the Doñana National Park seriously affected 
wild rabbit populations (Villafuerte et al. 1994) and caused high mortality rates. Thus, we were also able to investigate the possible effects of the decline in rabbit populations on the fecundity of Booted Eagle populations. Owing to the lack of comprehensive censuses of wild rabbit populations during the study period, we used prey remains found in nests during surveys to estimate both wild rabbit availability and prey diversity. All remains were identified to species level and so we knew year by year the species eaten by Booted Eagles and the number of items per species. We estimated the biomass of each prey from published data (for birds Cramp \& Simmons 1980, for hares Carro 2005, for rabbits Villafuerte 1994) and our own measurements for reptiles and mammals. The contribution of wild rabbits to the diet of Booted Eagles was estimated in the following two ways: as a proportion of total prey weight and as a proportion of total prey items. Prey diversity was considered to be the number of species found.

\section{Statistical analysis}

All variables were tested for normality with the Lilliefors test for samples with a priori unknown mean and standard deviation. When distribution was non-normal, non-parametric tests were used. The regulating mechanisms of the Booted Eagle population in Doñana National Park were explored using statisTICA 6 except when another program is specified. Statistical significance was set at Alpha $=0.05$.

One-way ANOVAS were used to compare population parameters or food availability between good and poor years, or between high and low population density periods. Breeding population size and annual fecundity, both over the entire population and distinguishing between territory qualities, were related using regression models. We selected the best model based on the Akaike index.

Nest-site dispersion was analysed per year with the GMASD statistic (Brown 1975) determined as the ratio between the geometric and arithmetic means of the squared averages of the minimum distances to the nearest neighbouring nests (Newton et al. 1977). G-statistic values ranged from 0 to 1 and values higher than 0.65 indicate regularity in nest spacing.

Generalized Linear Mixed Models (GLMMs, Littel et al. 1996) were used to identify the characteristics influencing the occurrence of brood reduction as per the method used by Serrano et al. (2001). The population was monitored over a number of years and adults showed a significant attachment to nest- sites, and so the macro GLIMMIX of SAS permitted us to fit nest and year as random terms in the GLMMs. Logistic regressions were developed to predict the probability of occurrence of brood reduction as a function of characteristics representing the nest or territory. The effects of hatching dates and territorial occupancy were evaluated separately. Brood reduction was modelled as a binomial response variable $(1=$ brood reduction, $0=$ no brood reduction) using a logistic link function (Kleinbaum 1994, So 1995, Kuss 2002).

The brood reduction frequency per year was related to the Booted Eagle population density and to rabbit availability by multiple regression models. We selected the best model based on the Akaike index.

Generalized Linear Models were used to identify the effects of hatching order and the siblinghood environment on the nutritional condition index, while controlling for the nest of birth and year. As in Ferrer (1993), we considered that chicks from the same nest were non-independent samples because of their common rearing environment. Therefore, nest was fitted as a random effect in the GLMM, as well as year. Nutritional condition index was modelled as a normal distribution and identity link. The explanatory variables were hatching order and siblinghood environment, of which the latter was divided in three categories: 1) nestlings reared alone, 2) nestlings reared alone after brood reduction, and 3) nestlings reared with a sibling. We used multiple regression models to examine the relationships between the yearly mean of urea residuals and fecundity, population density and brood reduction frequency. Among the possible best subsets we always chose that model with the lowest Akaike index.

\section{RESULTS}

\section{Mechanisms of population regulation}

The Booted Eagle breeding population in Doñana National Park increased during the study period (Fig. 2), from one pair in 1976 to 62 pairs in 1999 (in 2000, the last year of study, 60 pairs were recorded). At least 372 young fledged, 199 nests failed, and 87 nests had unknown fecundity as the nestlings were ringed before 30 days or at an unknown age. UTM locations were obtained for more than 500 nests within 79 territories.

Only data from the period 1983-2000 (inclusive) are used. Seventy-seven territories were occupied during this 18-year period, and the population increased from 13 breeding pairs in 1983 to 62 in 


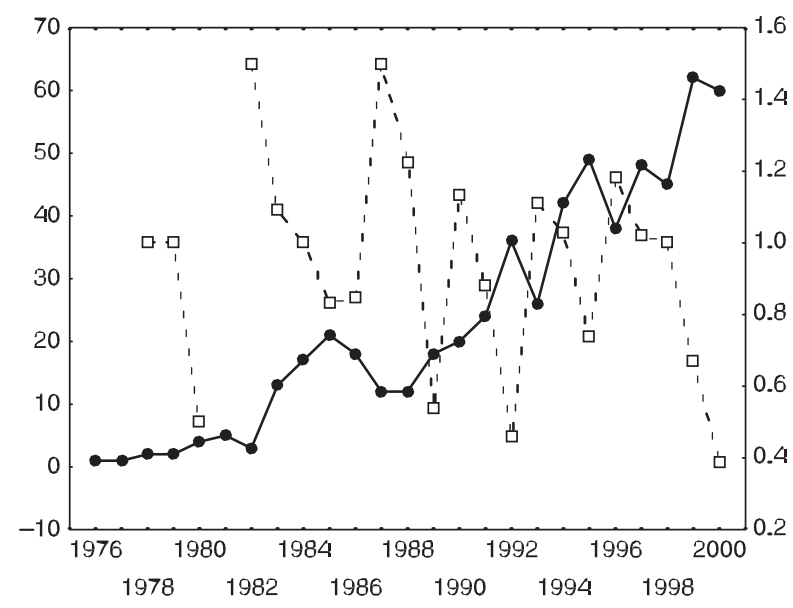

Figure 2. Annual changes in the size of the Booted Eagle population (continuous line) in Doñana National Park and its fecundity (dotted line) between 1976 and 2000.

1999. G-statistic values were lower than 0.60 for all years, indicating an irregular distribution of the nests. Nevertheless, values increased from 1983 to 2000 and were significantly correlated with the percentage of occupation ( $r=0.778, n=18, P<0.001)$, suggesting an increasingly regular distribution.

The mean population fecundity was 1.010 (sd = $\pm 0.277)$. A negative relationship between population fecundity and population size was detected $(r=-0.711, \quad \mathrm{df}=16, \quad P<0.001)$. The relationship was apparent both in old $(r=-0.657, \mathrm{df}=16$, $P=0.003)$ and in new territories $(r=-0.751, \mathrm{df}=7$, $P=0.02$ ). Population density appeared to have a weak effect on the fecundity of old territories during the low density period $(r=-0.600, \mathrm{df}=7, P=0.088)$, and there was no significant relationship between these territories in high density period ( $r=-0.566$, $\mathrm{df}=7, P=0.112$ ). Mean fecundity in low density periods was 1.111 (se $= \pm 0.072, n=135$ ) and 0.828 in high density periods (se $= \pm 0.039, n=378$ ). The distribution was increasingly right-skewed as fecundity decreased (Fig. 3).

The mean fecundity of territories was significantly related to their occupation frequency $(r=0.423$, $\mathrm{df}=76, P=0.0001$ ), being higher in more frequently occupied territories (Fig. 4). More frequently occupied territories showed earlier hatching dates than less frequently occupied ones $(r=-0.242, \quad \mathrm{df}=50$, $P=0.084)$. There was a significant relationship between occupation frequency and the year of first occupation $(r=-0.525, \mathrm{df}=76, P<0.001)$ : older territories were more frequently occupied during the study period.

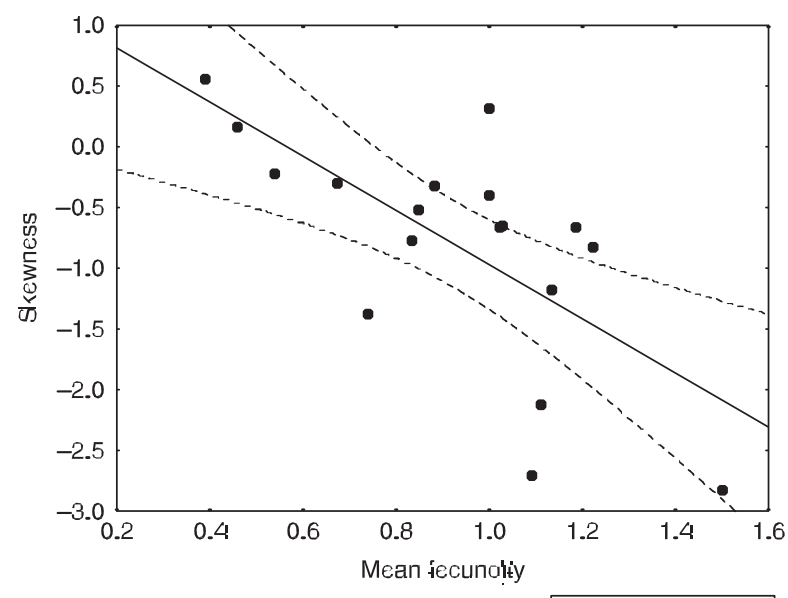

$95 \%$ conflatence

Figure 3. Relationship between mean fecundity and its skewness $(r=-0.676, \mathrm{df}=16, P=0.002)$.

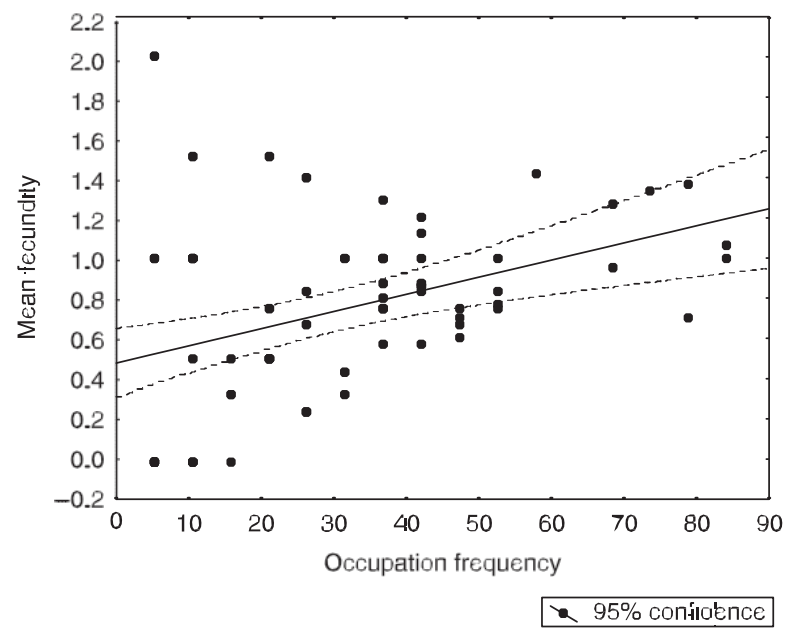

Figure 4. Relationship between territorial mean fecundity and occupation frequency $(r=0.385, \mathrm{df}=75, P=0.001)$ of the territory.

\section{Brood reduction}

Booted Eagles laid an average of $1.82 \pm 0.44$ eggs $(n=253)$ and the mean brood size at hatch was $1.21 \pm 0.82$ nestlings $(n=300)$. Brood reduction occurred in $35.5 \%$ of nests with at least two nestlings (mean $=0.36 \pm 0.48, n=121$ ). The most frequent age of nestling death $(n=4)$ was 3 days, although the mean age of death was 5.46 ( \pm 4.96 , range $0-19$ days). All the nestlings that died did so before reaching 11 days of age, except one that died at 19 days old.

As both measurements of rabbits in the diet were strongly correlated (Table 1), we chose for further analysis the one based on the number of items 
Table 1. Spearman rank order correlation values between the yearly parameters studied for 18 years.

\begin{tabular}{lccc}
\hline Variable & $\begin{array}{c}\text { Mean } \\
\text { fecundity }\end{array}$ & $\begin{array}{c}\% \\
\text { occupation }\end{array}$ & $\begin{array}{c}\% \text { rabbit } \\
\text { (weight) }\end{array}$ \\
\hline \% occupation & -0.437 & & \\
\% rabbit (by weight) & -0.376 & -0.416 & \\
\% rabbit (by items) & -0.121 & $-0.572^{\star \star}$ & $0.943^{\star \star \star}$
\end{tabular}

${ }^{\star *} P<0.01 ;{ }^{* \star *} P<0.001$

because it provided us with a larger sample size. The number of breeding pairs was the only variable included in the best model for explaining the yearly frequency of brood reduction (AIC $=-12.331, \mathrm{df}=1, P=0.0008$ ), and the two variables were positively correlated.

An ANOVA with year quality as a grouping variable showed that, although the laying rate did not differ between good and poor years, the hatching rate was significantly lower in poor years than in good ones $\left(F_{1,9}=7.49, P=0.02\right)$ and brood reduction frequency was significantly higher in poor years $\left(F_{1,9}=43.770\right.$, $P<0.001)$.

The hatching date tended to be earlier in territories with high occupancy (GLIMMIX with normal distribution and identity link), although not significantly $\left(F_{1,20}=3.48, P=0.076, n=116\right)$. We investigated the impact of hatching dates on demographic parameters averaged over the years for each territory (GLIMMIX with Poisson distribution and log link), and on brood reduction: the earlier the hatching date, the higher the clutch size $\left(F_{1,11}=27.06, P=0.0003\right.$, $n=93)$, the hatching rate $\left(F_{1,19}=5.20, P=0.034\right.$, $n=117$ ), and the number of fledglings excluding predated and fallen nests $\left(F_{1,18}=15.81, P<0.001\right.$, $n=109$ ). Brood reduction occurrence increased with season $\left(F_{1,4}=11.33, P=0.028, n=64\right)$, so that the later hatched broods were more likely to suffer reduction.

Reproductive parameters were positively and significantly related to territorial occupation frequency (clutch size: $r=0.235, n=68, P=0.05$; hatching rate: $r=0.406, n=68, P<0.001$; number of fledglings: $r=0.420, n=73, P<0.001$ ).

The occurrence of brood reduction was inversely related to the territorial occupation frequency $\left(F_{1,18}=\right.$ 4.99, $P=0.038$ ). The brood reduction frequency was $18.0 \%$ for those territories occupied in more than $70 \%$ of years, whereas it was $47.9 \%$ for the other territories. This confirms that the brood reduction frequency was significantly lower in the highest quality territories $\left(X^{2}=11.44\right.$, $\left.\mathrm{df}=1, P<0.001\right)$.
In summary, the best territories had higher breeding performance and less brood reduction. This corresponds to the relationship previously found between yearly fecundity and the brood reduction frequency.

\section{Biochemistry}

Urea and uric acid were correlated (Spearman correlation, $r_{s}=0.379, n=102, P<0.001$ ) and so we decided to use urea as an index of nutritional condition. As urea concentrations in nestlings are influenced by sex and age (Casado et al. 2002) and may be related to hatching date (Ferrer 2001 and references therein), we used the residuals obtained from an analysis of covariance (ANCOVA) as the index of nutritional condition, with urea as the dependent variable, sex as a factor, and age and hatching date as covariates $\left(F_{3,92}=\right.$ 5.29, $P=0.002, R^{2}=0.15, n=96$ nestlings). Urea residuals were distributed normally (Lilliefors test $P>0.20)$.

The best model explaining the nestlings' nutritional condition was that including nest and 'hatching order' (AIC $=350.924, \mathrm{df}=33, P=0.00001$ ): the first hatched chick (mean $=-2.131$, se $= \pm 1.273$, $n=30$ ) had a better nutritional condition than its sibling (mean $=0.866$, se $= \pm 2.140, n=23$ ). There were significant differences in nutritional condition between good and poor years (Wald $X_{3}^{2}=22.01$, $P<0.0001$ ), the nutritional condition being worse in good years (1997: mean $=0.861$, se $= \pm 1.537$, $n=19 ;$ 1998: mean $=1.991$, se $= \pm 3.472, n=14$ ) than in poor ones (1999: mean $=-3.280$, se $= \pm 3.272$, $n=5$; 2000: mean $=-4.789$, se $= \pm 0.964, n=15$ ). No effect of siblinghood environment was detected.

The model best explaining the yearly nutritional condition of the nestlings was that including brood reduction frequency, population density and fecundity (AIC $=9.492, \quad \mathrm{df}=3, P<0.0001$ ). Urea residuals decreased with increasing population size and brood reduction frequency, and with decreasing mean fecundity.

Biochemical samples were obtained from 55 adults, although many of these birds were from nests for which we had no information on brood reduction, reducing our sample size to 30 individuals (15 females and 15 males). The GLIMMIX model did not converge (with year as random factor) and so we used the Generalized Linear Model Module of STATISTICA (a bias due to the year effect is possible) with a binomial distribution, the logit link function, and the overdispersion parameter whenever necessary. We used age and urea as estimates of parental quality. Analyses were carried out separately according to 
sex, as parental roles differ and hence the parental effect on brood reduction may also differ. We did not find any significant effect on brood reduction in either of the two sexes.

\section{Food abundance}

The frequency of rabbits in the diet decreased over the years $(r=0.647, n=18, P<0.005)$, but this did not affect population fecundity (Table 1 ). Nevertheless, the proportion of rabbits in the diet differed significantly before and after 1990 (outbreak of wild rabbit hemorrhagic disease) at $43.04 \%$ and $23.44 \%$, respectively (one-way ANova, $F_{1,16}=15.247, P<0.005$ ). A negative correlation between diet diversity and the proportion of rabbits in the diet $(r=0.617, n=18$, $P<0.01$ ) was also found.

The brood reduction frequency in selected years was negatively related to the percentage of rabbits in the diet $(r=-0.710, n=11, P<0.025)$.

\section{DISCUSSION}

The Booted Eagle population in Doñana National Park has grown considerably since the first birds nested in 1976 and it was still increasing at the end of our study period. This fits a general trend across Western Europe (Carlon 1996). Only fairly approximate estimates of population sizes in other countries are available, although most are apparently stable (del Hoyo et al. 1994); likewise, trends are unknown in most of Spain as regular censuses have never been carried out. A population decrease has been recorded in one province (Madrid), whereas populations are increasing in other regions such as Catalonia, Extremadura, and Murcia (Bosch 2003, Martí \& Del Moral 2003). The increase of the Booted Eagle population in Doñana National Park seems to be above average compared with that of other known areas.

This increase is generally assumed to be a consequence of the species' capacity to adapt to environmental change (Carlon 1996, Suárez-Seoane et al. 2000). Evidence of this adaptable nature is its flexibility in prey choice: when wild rabbit hemorrhagic disease reduced the availability of the Booted Eagle's main prey, it was able to catch many other prey species, as suggested by the inverse relationship between the remains of wild rabbits and other prey items found in nests. The reduced availability of wild rabbits only affected those nests in low quality territories, where perhaps other prey species were also scarce. Years with lower fecundity than the total mean fecundity were characterized by a lower hatching rate. Furthermore, brood reduction was more frequent in less productive years. The relationship between the yearly frequency of brood reduction and the percentage of rabbits in the diet suggests that the role of brood reduction in population regulation is stronger when food availability diminishes.

The increase in the number of breeding pairs was accompanied by an increase in brood reduction frequency and a decrease in fecundity, which reveals the density-dependent nature of brood reduction. At the same time, the nests were irregularly distributed but became more regularly distributed with time.

Our results suggest that in the Doñana Booted Eagle population, habitat heterogeneity is the regulating mechanism that reduces the rate of population increase when the population density is high, although interference among individuals could work in periods of low density; both mechanisms could regulate the fecundity of the studied Booted Eagle population, albeit at different stages. Occupation frequency was used as a measure of territorial quality in this study: the most frequently used territories showed higher fecundity rates, a more right-skewed fecundity, and were generally occupied earlier in the study period. This demonstrates that there are different territory qualities in the study area. Furthermore, the older territories (also considered those of high quality), as opposed to new ones, did not seem to be affected by population increase in high density periods, which supports the HHH. Nevertheless, there was a tendency for fecundity in older territories to be negatively affected by the increase in population size in low density periods. This supports the idea that, when all the breeding pairs are nesting in a homogeneous patch of high quality territories and the population is growing, the interference among individuals reduces the fecundity rate, as demonstrated by Rodenhouse et al. (2003). In fact, this interference in an increasing population would force some individuals to move into poorer territories where habitat heterogeneity would start to be the main regulating mechanism of fecundity. Consequently, the trend towards yearly decreases in fecundity can be explained by an increasing number of new pairs nesting in low quality territories, as has been shown for the Spanish Imperial Eagle Aquila adalberti (Ferrer \& Donázar 1996). These findings are consistent with the theory that the Booted Eagle population of Doñana is actually regulated through source-sink dynamics generated by density dependence in fecundity through habitat 
heterogeneity (Newton 1991, Ferrer \& Donázar 1996). Under this model, in which a relatively small number of territories may sustain a much larger population, conservation plans must take into account the fact that disturbances have different consequences on population viability depending on the quality of the territories affected. The same impact could be negligible in sink territories or determinant in source ones (Ferrer \& Donázar 1996, Sergio \& Newton 2003).

As the Booted Eagle is a migratory bird, conditions during the non-breeding season will also contribute to fluctuations in the breeding population size, but the processes operating during the breeding period are sufficient for regulating the population of a migratory species (Rodenhouse et al. 2003).

Factors others than territory quality, such as the individual quality of breeders, the fact that higher quality individuals occupy the best territories, and the age of breeders, may all affect demographic parameters (Ferrer \& Bisson 2003, Penteriani et al. 2003, Carrete et al. 2006). It is difficult to separate clearly individual effects from that of habitat quality on breeding performance (Newton 1991, Ferrer \& Donázar 1996, Rodenhouse et al. 1997, Krüger \& Lindström 2001, Ferrer \& Bisson 2003, Ferrer et al. 2006). In this case, the duration of the study period was longer than the life spans of most Booted Eagle individuals (mean lifespan of a Booted Eagle $=7.95$ years, sd $= \pm 3.623$, ringing center of Doñana Biological Reserve Archives) and so the $\mathrm{HHH}$ undoubtedly helps explain the observed trends in fecundity. Based on a 7-year study, Martínez et al. (2006) showed that a given territory with successful previous reproductive events had a higher probability of being occupied by a Booted Eagle, a finding that is consistent with our results (more productive territories are more frequently used). Nevertheless, the authors concluded that individual quality could be the main factor affecting population fecundity, without showing individualized data of breeding birds (e.g. age, ring number, territory occupied every year), which undermines that conclusion. As other raptor studies have demonstrated that individuals move into better territories when they are able, for example through the loss or emigration of one of the partners (Ferrer \& Bisson 2003, Penteriani \& Ferrer 2004), it would be interesting to conduct more comprehensive studies on Booted Eagles.

For many birds, fecundity decreases as laying dates get later (e.g. Hochachka 1990, Ferrer 1993, Penteriani 1997). In the case of the Booted Eagle, both reproductive parameters and brood reduction frequencies were linked to hatching dates. This is commonly interpreted as being a result of a seasonal decline in food availability during the breeding season, which may increase brood reduction frequency because food shortage would encourage siblicide (review by Forbes \& Mock 1994, Drummond 2001 and references therein). Nevertheless, the abundance of wild rabbit in Doñana National Park is at its peak in June and December, and at its lowest in October (Beltrán 1991). Thus, pairs raising chicks later on in the season (mean laying date was April $22 \pm 12.75$ days, $n=69$; the earliest laying date was 2 April and the latest 2 June; $43.48 \%$ of clutches were laid between 10 and 20 April) would find more favourable conditions. Bigger differences in wild rabbit abundances were found between habitats than between months (Beltrán 1991, Lombardi et al. 2003). Other possible explanations could relate to adult physical condition. Those individuals in better condition would be able to start reproduction soon after arrival and earlier than others. Unfortunately, the Booted Eagle is difficult to capture before their eggs hatch (we only captured two individuals from two breeding pairs) and so we were unable to take blood samples to study their physical condition just after arriving on their breeding grounds. It would be interesting in the future to investigate the relationship between adult condition at the beginning of the breeding season and fecundity.

Biochemical blood analysis indicated that nestling physical condition varied between territories. Furthermore, the first chicks to hatch were better nourished than their younger siblings. This probably means that either feeding rates are biased towards older nestlings (parental decision) or older siblings have the capacity to dominate their nest-mates during meals through more begging signals and/or aggression (nestling decision). Indeed, parents typically feed first those nestlings that beg at higher intensities and/ or who are closer to them (Budden \& Wright 2001). In addition, Drummond and Garcia Chavelas (1989) suggested that poor nutritional conditions would increase the aggressiveness of the older chick. This could lead to the death of the younger chick through siblicide. In the best territories, the first chick would be satiated earlier and the second would eat enough to survive, whereas in the worst territories the first chick would go hungry and attack its brood mate to appropriate more food. Nevertheless, the operating mechanism that enhances brood reduction still needs further research.

We observed no differences in nutritional condition between the three kinds of rearing environment (see 
Methods). Thus, the remaining nestlings after brood reduction have no advantage in comparison with situations in which both nestlings survive. Ploger (1997) even found a decrease in food brought to nests with reduced broods. However, Simmons (2003) reanalysed the experimental data for raptors and found that parents did not reduce food supplies after brood reduction and so, in a two-chick nest, the surviving chick should get more food than before the elimination of its sibling. The better nutritional condition of nestlings in a growing population, when fecundity is decreasing and brood reduction is increasing, could be related to a higher proportion of low quality territories being occupied. This is in accordance with the result obtained when we analysed the nutritional condition by nest. In years of higher fecundity (1997-98), more fledglings were raised but in worse average nutritional condition because low quality territories were also successful, whereas in poor years (1999-2000), when most of the fledglings flew from high quality territories, fewer fledglings were raised but in better nutritional condition. No parental effect was noticed on the occurrence of brood reductions. However, we consider that our sample size is too low to draw any conclusions regarding this trend.

Our study indicates that brood reduction occurred mainly in the worst territories. Thus, an increase in brood reduction is probably a consequence of the increasing usage of worse quality territories under higher population densities. In this sense, brood reduction could be considered a consequence of the regulation of populations by habitat heterogeneity and of food shortage. As the nestlings dying as a result of brood reduction belong to the subset of those born in the worst territories and later on in the year (and thus with fewer possibilities of reaching reproductive age), the real effect of brood reduction on population dynamics may be smaller than the number of nests affected suggests.

We are indebted to ICONA and the RBD fieldworkers who have monitored Booted Eagle fecundity in Doñana National Park for 20 years and, above all, to Luis Garcia, who also spent much of his time showing us every old nest once occupied by the species, and Javier Balbontin, who conducted the monitoring work for 3 years. We are also grateful to A. Dekker for helping with the fieldwork for a year during his ethological research project (Zoological Laboratory, University of Groningen). G. Högstedt, R. Simmons, M. Stenning, P. Whitfield and two anonymous referees greatly improved the original manuscript.

\section{REFERENCES}

Andrewartha, H.G. \& Birch, I.C. 1954. The Distribution and Abundance of Animals. Chicago: University of Chicago Press.

Beltrán, J.F. 1991. Temporal abundance patterns of the wild rabbit in Doñana, SW Spain. Mammalia 55: 591-599.

Bosch, J. 2003. Fenología y parámetros reproductivos del Aguililla Calzada Hieraaetus pennatus en Cataluña Central (España). Ardeola 50: 181-189.

Both, C. 1998. Density dependence of clutch size: habitat heterogeneity or individual adjustment? J. Anim. Ecol. 67: 659-666.

Brown, D. 1975. A test of randomness of nest spacing. Wildfowl 26: 102-103.

Budden, A.E. \& Wright, J. 2001. Begging in nestling birds. Curr. Ornithol. 16: 83-118.

Carlon, J. 1996. Response of Booted Eagles to human disturbance. Br. Birds 89: 267-274.

Carrete, M., Sánchez-Zapata, J.A., Tella, J.L., Gil-Sánchez, J.M. \& Moleón, M. 2006. Components of breeding performance on two competing species: habitat heterogeneity, individual quality and density-dependence. Oikos 112: 680-690.

Carro, F. 2005. Historia Natural de la Liebre ibérica en el Parque Nacional de Doñana. PhD Thesis, University of Santiago de Compostela.

Casado, E., Balbontin, J. \& Ferrer, M. 2002. Plasma chemistry in Booted Eagle (Hieraaetus pennatus) during breeding season. Comp. Biochem. Physiol. 131A: 233-241.

Cramp, S. \& Simmons, K.L. (eds) 1980. The Birds of the Western Palearctic, Vol. 2. Oxford: Oxford University Press.

Dhondt, A.A., Kempenaers, B. \& Adriaensen, F. 1992. Density-dependent clutch size caused by habitat heterogeneity. J. Anim. Ecol. 61: 643-648.

Drummond, H. 2001. A revaluation of the role of food in broodmate aggression. Anim. Behav. 61: 517-526.

Drummond, H. \& Garcia Chavelas, C. 1989. Food shortage influences sibling aggression in the Blue-footed Booby. Anim. Behav. 37: 806-819.

Edwards, T.C. \& Collopy, M.W. 1983. Obligate and facultative brood reduction in eagles: an examination of factors that influence fratricide. Auk 100: 630-635.

Fernandez, C., Azkona, P. \& Donázar, J.A. 1998. Densitydependent effects on fecundity in the Griffon Vulture Gyps fulvus: the role of interference and habitat heterogeneity. Ibis 140: 64-69.

Ferrer, M. 1993. Ontogeny of dispersal distances in young Spanish imperial eagles. Behav. Ecol. Sociobiol. 32: 259-263.

Ferrer, M. 1994. Nutritional condition of Spanish Imperial Eagle nestlings Aquila adalberti. Bird Study 41: 120-123.

Ferrer, M. 2001. The Spanish Imperial Eagle. Barcelona: Lynx Edicions.

Ferrer, M. \& Bisson, I. 2003. Age and territory quality effects on fecundity in Spanish Imperial Eagle (Aquila adalberti). Auk 120: $180-186$.

Ferrer, M. \& Donázar, J.A. 1996. Density-dependent fecundity by habitat heterogeneity in an increasing population of Spanish Imperial Eagle. Ecology 77(1): 69-74.

Ferrer, M., Newton I. \& Casado, E. 2006. How to test different density-dependent fecundity hypotheses in an increasing or stable population. J. Anim. Ecol. 75: 111-117.

Ferrer, M., Newton I. \& Casado, E. 2008. Density dependence hypotheses and the distribution of fecundity. J. Anim. Ecol. 77: 341-345. 
Forbes, L.S. \& Mock, D.W. 1994. Proximate and ultimate determinants of avian brood reduction. In Parmigiani, S. \& von Saal, F.S. (eds) Infanticide and Parental Care: 237-256. Switzerland: Chur, Harwood.

Fretwell, S.D. \& Lucas, H.L. 1970. On territorial behaviour and other factors influencing habitat distribution in birds, theoretical development. Acta Biotheoretica 19: 16-36.

Goodburn, S.F. 1991. Territory quality or bird quality? Factors determining breeding success in the Magpie Pica pica. Ibis 133: 85-90.

Haller, M. 1996. Der Steinadler in Graubünden. Langfristige Untersuchungen zur Populationsökologie von Aquila chrysaetos im Zentrum der Alpen. Orn. Beob. 9: 1-167.

Hochachka, W. 1990. Seasonal decline in reproductive performance of song sparrows. Ecology 71: 1279-1288.

Horne, G. \& Fielding, A.H. 2002. Recovery of the Peregrine Falcon Falco peregrinus in Cumbria, UK, 1966-99. Bird Study 49: 229-236.

del Hoyo, J., Elliott, A. \& Sargatal, J. 1994. Handbook of the Birds of the World, Vol. 2. Barcelona: Lynx Edicions.

Kleinbaum, D.G. 1994. Logistic Regression: A Self-learning Text. New York: Springer.

Krüger, O. \& Lindström, J. 2001. Habitat heterogeneity affects population growth in Goshawk Accipiter gentilis. J. Anim. Ecol. 70: 173-181.

Kuss, O. 2002. How to use SAS for logistic regression with correlated data. Proceedings of the 27th Annual SAS Users Group International Conference (SUGI 27): 261-275.

Lack, D. 1947. The significance of clutch size. Ibis 89: 302-352.

Lack, D. 1954. The Natural Regulation of Animal Numbers. Oxford: Oxford University Press.

Lack, D. 1966. Population Studies of Birds. Oxford: Clarendon Press.

Littel, R.C., Milliken, G.A., Stroup, W.W. \& Wolfinger, R.S. 1996. SAS System for Mixed Models. Cary, NC: SAS Institute Inc.

Lombardi, L., Fernández, N., Moreno, S. \& Villafuerte, R. 2003. Habitat-related differences in rabbit (Oryctolagus cuniculus) abundance, distribution, and activity. J. Mammal. 84: $26-36$.

Martí, R. \& Del Moral, J.C. 2003. Atlas de las aves reproductoras de España. Madrid: Dirección General de la Conservación de la Naturaleza \& SEO/Birdlife.

Martínez, J.E. \& Calvo, J.F. 2005. Prey partitioning between mates in breeding Booted Eagles (Hieraaetus pennatus). J. Raptor Res. 39: 159-163.

Martínez, J.E., Cremades, M., Pagán, I. \& Calvo, J.F. 2004. Diet of Booted Eagles in southeastern Spain. In Chancellor, R.D. \& Meyburg, B.-U. (eds) Raptors Worldwide: 593-599. Budapest: World Working Group on Birds of Prey \& MMD/ BirdLife Hungary.

Martínez, J.E., Pagán, I. \& Calvo, J.F. 2006. Factors influencing territorial occupancy and reproductive output in the Booted Eagle Hieraaetus pennatus. Ibis 148: 807-819.

Mock, D.W. \& Forbes, L.S. 1995. The evolution of parental optimism. Trends Ecol. Evol. 10: 130-134.

Newton, I. 1979. Population Ecology of Raptors. London: T. \& A.D. Poyser.

Newton, I. 1991. Habitat variation and population regulation in Sparrowhawks. Ibis 133: 76-88.

Newton, I., Marquiss, M., Weir, D.N. \& Moss, D. 1977. Spacing of Sparrowhawk nesting territories. J. Anim. Ecol. 46: 425-441.

Newton, I., Rothery, P. \& Dale, L.C. 1998. Density-dependence in the bird populations of an oak wood over 22 years. Ibis 140: 131-136.
Penteriani, V. 1997. Long-term study of a goshawk breeding population on a Mediterranean mountain (Abruzzi Apennines, Central Italy): density, breeding performance and diet. J. Raptor Res. 31: 308-312.

Penteriani, V. \& Ferrer, M. 2004. Unpaired female birds use sex to attract already paired males: 'La donna è mobile qual piuma al vento'. Ethol. Ecol. Evol. 16: 91-95.

Penteriani, V., Gallardo, M. \& Roche, P. 2002. Landscape structure and food supply affect Eagle Owl (Bubo bubo) density and breeding performance: a case of intra-population heterogeneity. J. Zool., Lond. 257: 365-372.

Penteriani, V., Balbontin, J. \& Ferrer, M. 2003. Simultaneous effects of age and territory quality on fecundity in Bonelli's Eagle Hieraaetus fasciatus. Ibis 145 (online): E77-E82.

Ploger, B.J. 1997. Does brood reduction provide nestling survivors with a food bonus? Anim. Behav. 54: 1063-1076.

Pulliam, H.R. \& Danielson, B.J. 1991. Sources, sinks, and habitat selection: a landscape perspective on population dynamics. Am. Nat. 137: s50-s66.

Rodenhouse, N.L., Sherry, T.W. \& Holmes, R.T. 1997. Sitedependent regulation of population size: a new synthesis. Ecology 78: 2025-2042.

Rodenhouse, N.L., Sillett, T.S., Doran, P.J. \& Holmes, R.T. 2003. Multiple density-dependence mechanisms regulate a migratory bird population during the breeding season. Proc. R. Soc. Lond. B 270: 2105-2110.

Sánchez-Zapata, J.A. \& Calvo, J.F. 1999. Raptor distribution in relation to landscape composition in semi-arid Mediterranean habitats. J. Appl. Ecol. 36: 254-262.

Sergio, F. \& Newton, I. 2003. Occupancy as a measure of territory quality. J. Anim. Ecol. 72: 857-865.

Serrano, D., Tella, J.L., Forero, M.G. \& Donázar, J.A. 2001. Factors affecting breeding dispersal in the facultatively colonial Lesser Kestrel: individual experience vs. conspecific cues. J. Anim. Ecol. 70: 568-578.

Simmons, R. 1988. Offspring quality and the evolution of cainism. Ibis 130: $339-357$.

Simmons, R. 2003. Siblicide provides food benefits for raptor chicks: re-evaluating brood manipulation studies. Anim. Behav. 63: 19-24.

Sinclair, A.R.E. 1989. Population regulation in animals. In Cherret, J.M. (ed.) Ecological Concepts: 197-241. Oxford: Blackwell Scientific.

So, Y. 1995. A Tutorial on Logistic Regression. Cary, NC: SAS Institute Inc.

Suárez-Seoane, S., Balbontin, J. \& Ferrer, M. 2000. Nesting habitat selection by Booted Eagles Hieraaetus pennatus and implications for management. J. Appl. Ecol. 37: 215-223.

Veiga, J.P. 1986. Food of Booted Eagle (Hieraaetus pennatus) in central Spain. J. Raptor Res. 20: 120-123.

Villafuerte, R. 1994. Riesgo de depredación y estrategias defensivas del conejo, Oryctolagus cuniculus (L.), en el Parque Nacional de Doñana. PhD Thesis, University of Córdoba, Spain.

Villafuerte, R., Calvete, C., Gortazar, C. \& Moreno, S. 1994. First epizootic of rabbit hemorrhagic disease in free living populations of Oryctolagus cuniculus at Doñana National Park, Spain. J. Wild. Dis. 30: 176-179.

Viñuela, J. 1999. Sibling aggression, hatching asynchrony, and nestling mortality in the Black Kite (Milvus migrans). Behav. Ecol. Sociobiol. 45: 33-45. 